\title{
A Desigualdade das Mulheres no Mundo do Trabalho: um Breve Histórico da Presença das Mulheres no Mundo do Trabalho e na Disciplina de Relações Internacionais
}

\author{
Caroline Delgado da Silva ${ }^{1}$
}

\section{Resumo}

Este trabalho busca demonstrar a discriminação que sofrem as mulheres no campo de trabalho no mundo. Além de compreender os desdobramentos da disciplina de Relações Internacionais, referentes à problematização do gênero feminino quanto à emancipação da mulher, buscando entender esse problema como um problema global e não apenas regional característico de alguns lugares. A discriminação sofrida em decorrência do gênero feminino não nos é singular, porém cabe aqui questionar como as mulheres vêm enfrentando esse problema no âmbito do mercado de trabalho. Busca-se compreender como se dão os movimentos das mulheres no mundo, que conquistaram e vêm conquistando sua autonomia. A escolha desse tema vem do interesse em questionar a própria evolução do feminismo nas Relações Internacionais e a participação das mulheres no mundo do trabalho, além de também buscar abordar perspectivas que vão além das tradicionais.

Palavras chave: Feminismo, Marxismo, Relações Internacionais, Mulheres.

\section{Abstract}

This paper seeks to demonstrate the discrimination suffered by women in the field of work in the world. In addition to understanding the developments of the discipline of International Relations, referring to the problematization of the feminine as to the emancipation of women, seeking to understand this problem as a global problem and not only regional, characteristic of some places. Discrimination suffered as a result of the female gender is not unique; however, it is necessary to question here how women are facing this problem within the labor market. It also seeks to understand how the movements of women in the world, which have conquered and come to gain their autonomy, are being sought. The choice of this theme comes from the interest in questioning the very evolution of feminism in International Relations and the participation of women in the world of work, as well as seeking to approach perspectives that go beyond traditional ones.

Keywords: Feminism, Marxism, International Relations, Women.

Introdução

${ }^{1}$ Graduada em Relações Internacionais pelo Centro Universitário Ritter dos Reis - Uniritter. Email: caroline.delgado@outlook.com. 
Os debates iniciados durante as décadas de 1980 e 1990, dentro das Relações Internacionais, abrangeram novas perspectivas dentro da área, buscando ir além das teorias tradicionais (NOGUEIRA e MESSARI, 2005). A visão das teorias tradicionais pretendia compreender o fenômeno da guerra, a fim de evitar tragédias devastadoras semelhantes a Primeira Grande Guerra, buscando responder quais as causas do confronto e também como alcançar a paz (SARFATI,2005). A busca por entender o mundo como ele deve ser e não como ele realmente é, está creditada aos idealistas que foram considerados utópicos por essa visão. Já os realistas entendiam o mundo com uma visão menos utópica, voltada mais para questões de interesse e de poder.

A evolução da disciplina se deu baseada na visão realista que se caracterizou por explicar melhor, naquele momento, o funcionamento da política mundial. A ausência de teorias que esclarecessem as transformações políticas além das visões anteriores deu impulso para novos autores na disciplina (NOGUEIRA e MESSARI, 2005). Dessa forma, também havendo a falta de alternativas que pudessem compreender o mundo para além do pensamento predominantemente masculino (focado em temas como poder segurança, guerra-paz, estabilidade e soberania estatal) traçam-se abordagens que buscam entender a problemática de gênero.

A linha teórica feminista das Relações Internacionais compreende a desigualdade de gênero como um problema mundial, que deve ser tratado como tal. A OIT (Organização Internacional do Trabalho) avaliou entre 1995 e 2015 as disparidades de gênero na participação da força de trabalho e concluiu que as taxas de emprego diminuíram apenas marginalmente nesse período. A taxa de atividade global da população feminina diminuiu de 52,4 por cento para 49,6 por cento, enquanto que os números correspondentes para os homens são respectivamente de 79,9 e 76,1 por cento. As oportunidades para as mulheres permanecem quase 27 pontos abaixo das oportunidades em relação aos homens. A entidade ainda afirma que as taxas mais baixas de participação das mulheres traduzem-se em menos oportunidades de emprego, com poucas variações ao longo do tempo, o que afeta negativamente a capacidade de sustento e de manter sua segurança econômica. Em 2015, esses números atingiram 25,5 pontos em prejuízo das mulheres, apenas 0,6 pontos menos do que em 1995 (OIT,2016).

Essa desigualdade é o objeto de estudo deste trabalho, ressaltando que essa ocorre em vários setores da sociedade e que, portanto, é necessário discuti-la a fim de entendê-la. Buscase com esta pesquisa demonstrar como se dão esses movimentos emancipatórios no mundo, 
dentro da lógica do feminismo como perspectiva alternativa das Relações Internacionais, um campo pouco explorado por mulheres, por ser uma área predominantemente masculina.

O tema aqui abordado justifica-se na medida em que trata de um problema contemporâneo e de grande impacto para as Relações Internacionais no que tange as questões sobre gênero e identidade e de que forma a emancipação da classe trabalhadora, em especial das mulheres, contribui para a relevância do debate da teoria feminista na disciplina de RI (Relações Internacionais). A desigualdade sofrida pelas mulheres tornou-se objeto de pesquisa das Nações Unidas, e parte da agenda de mudanças para o desenvolvimento, mostrando o quão relevante é este assunto.

Segundo Engels (2009), a desigualdade de gênero dentro da esfera doméstica só foi acentuada pelo sistema capitalista, que acabou tornando a mulher duplamente explorada, pois a ela está designado o papel da reprodução, além das responsabilidades domésticas, ao mesmo tempo em que há a liberdade de ingressar no campo de trabalho.

Simone de Beauvoir (2010) afirma que a igualdade só se poderá restabelecer quando os dois sexos tiverem direitos juridicamente iguais, mas essa libertação exige a entrada de todo o sexo feminino na atividade pública. E cita Engels, "A mulher só se emancipará quando puder participar em grande medida social na produção, e não for mais solicitada pelo trabalho doméstico senão numa medida insignificante. E isso só se tornou possível na grande indústria moderna, que não somente admite o trabalho da mulher em grande escala como ainda o exige formalmente..." (ENGELS apud BEAUVOIR, 2010, p.75). A autora complementa que "deste modo, o destino da mulher e o socialismo estão intimamente ligados" (BEAUVOIR, 2010, p.75). Torna-se importante lembrar que as obras de Engels e Beauvoir datam dos séculos XIX e XX, mas mostram-se muito atuais, dessa forma, torna-se importante dialogar com tais obras nesse artigo.

Também cabe ressaltar que, nas últimas décadas, os movimentos feministas conduziram diversas mudanças culturais e políticas, levando as ciências humanas a lançarem luzes aos processos de transformação da condição de gênero nos diversos países do continente. Mais recentemente, Brasil, Argentina e Chile chamaram especial atenção por elegerem mulheres para a Presidência da República e terem lançado uma série de ações governamentais voltadas para questões de gênero.

Este trabalho caracteriza-se em uma pesquisa descritiva que busca principalmente descrever, analisar ou verificar as relações entre fatos e fenômenos estudados. Também será 
qualitativa, pois identifica e analisa dados não mensuráveis numericamente, como sentimentos, sensações, percepções e intenções.

\section{As mulheres no mundo do trabalho}

Para ilustrar melhor como é o mundo do trabalho para as mulheres, nesta seção iremos observar as diferenças enfrentadas por elas, e como ocorre a inserção delas no mercado. A autora francesa Michelle Perrot diz em seu livro, Minha História das Mulheres, que as mulheres sempre trabalharam nos trabalhos domésticos não remunerados e não valorizados e afirma que as sociedades jamais poderiam ter se desenvolvido sem o trabalho doméstico das mulheres, que é invisível. As mulheres camponesas são a primeira expressão de mulheres trabalhadoras fora do campo doméstico, ligadas aos trabalhos rurais, no período que precedeu a Segunda Guerra mundial, essa era a condição de quase metade das mulheres na França, afirma a autora. E, certamente, ainda é a condição da maioria em regiões como África, Ásia e América Latina (PERROT, 2017). De fato as percepções da autora são relevantes e atuais, ao passo que ainda vemos o trabalho doméstico como única e exclusivamente tarefa feminina.

No livro A Era dos Impérios, Eric Hobsbawm dedica um capítulo para tratar dos trabalhadores, porém não menciona explicitamente, em seu texto, as massas de mulheres presentes nessa classe. E apesar de apresentar um capítulo que trata apenas das mulheres da classe burguesa, é possível encontrar várias imagens que retratam as mulheres na sociedade durante os anos de 1875 a 1914, sendo algumas dessas, mulheres da classe trabalhadora. Reafirmando a ideia de que as mulheres sempre estiveram presentes no trabalho fora do lar. A seguir, uma das imagens que retratam as mulheres camponesas à época: 


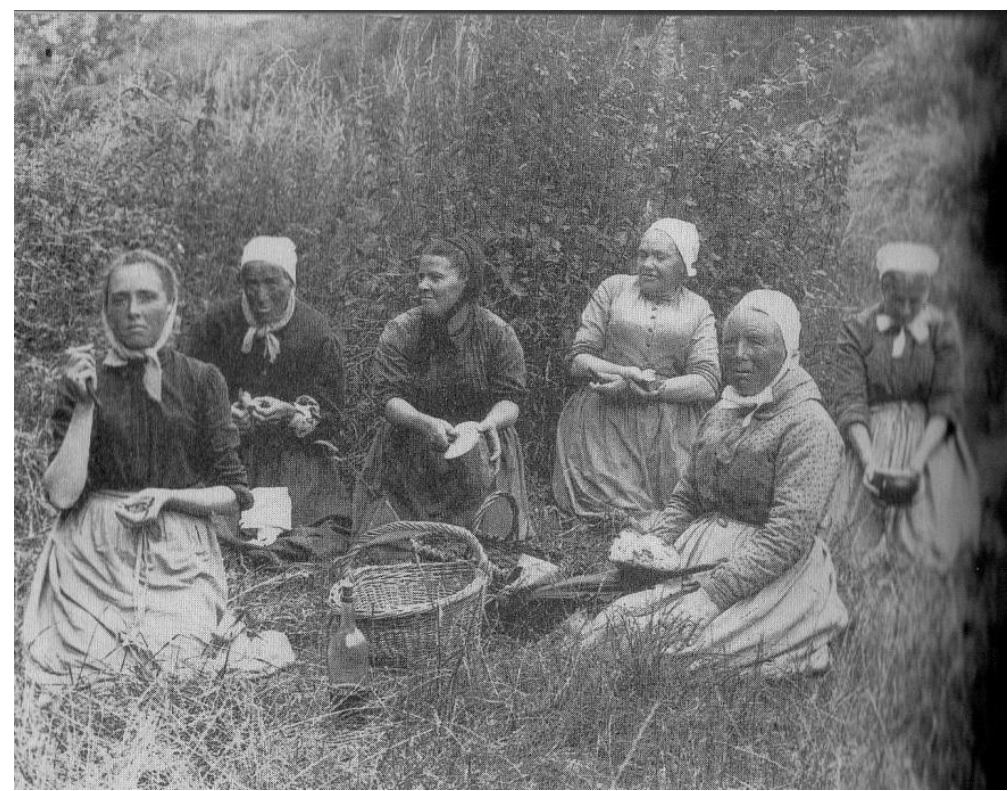

Figura 1. Camponesas comendo durante o trabalho em uma cidade da França.

Fonte: Eric Hobsbawm.

Michelle Perrot afirma também que a vida das mulheres mudou com a guerra, em particular com a Primeira Guerra Mundial, quando houve um grande êxodo rural, o que acabou transferindo as responsabilidades do campo para elas. Nesse momento, elas aprendem a lavrar a terra e a gerenciar os negócios. Porém as mulheres também fizeram parte do êxodo rural, pois as mulheres jovens agora trabalhavam como criadas na cidade, além de serem inseridas nos trabalhos nas fábricas também. Essas fábricas se tornavam dormitório para essas jovens, onde permaneciam por meses sem ir para casa, e suas famílias é que recebiam diretamente seus salários. Esse dinheiro era muito valorizado, o que gerava estima pela contribuição feminina na economia familiar (PERROT, 2017).

No período da industrialização, as mulheres se inseriram no mercado de trabalho, sendo delas grande parte das funções e lugares não qualificados. A divisão do trabalho, portanto, se estabeleceu com a justificativa de que as mulheres não possuíam o conhecimento técnico para supervisionar os serviços. São essas posições fragmentadas do saber fazer e do ter o conhecimento técnico para determinado ofício, e, consequentemente, a valorização e remuneração dos respectivos trabalhos, que fazem com que as mulheres se organizem na tentativa de estabelecer relações igualitárias entre homens e mulheres no mundo do trabalho (TEIXEIRA, p. 238, 2009).

A falta desses conhecimentos e a estigma criada em cima das mulheres que os possuíam, podem ser entendidos como fatores que mantiveram por tanto tempo as mulheres nos trabalhos menos valorizados. O que justifica que nesse momento, as jovens buscassem 
por mais liberdade, o que deu impulso para alcançarem outros campos de trabalho. Nos séculos XVIII e XIX torna-se evidente a importância do trabalho doméstico na vida das famílias e das sociedades, dessa forma os economistas veem na dona de casa o equilíbrio econômico familiar. As mulheres é que possuem o controle do orçamento familiar, agindo como "ministro das finanças". O marido lhes entrega o pagamento da semana e elas são responsáveis por manterem a casa em ordem (PERROT, 2017). Essa ideia está presente também em Engels (2009).

Porém, é importante ressaltar que esse é o papel da dona de casa dos meios operários. A dona de casa burguesa, no entanto, por ter melhores condições financeiras, possui as chamadas "criadas", que são mulheres que se encarregam de fato do trabalho pesado, enquanto que a dona da casa as ordena. Esse sistema garantia uma posição bem acima no seu status perante à sociedade. Uma mudança na posição social e as expectativas das mulheres tornou-se óbvia nas últimas décadas do século XIX, considerou que os aspectos mais visíveis da emancipação das mulheres ainda eram largamente confinados às mulheres da classe média (HOBSBAWM, 1989, p. 201).

Simone de Beauvoir afirma que, no século XIX, a querela do feminismo torna-se novamente uma querela de sectários; uma das consequências da revolução industrial é a participação da mulher no trabalho produtor: nesse momento as reivindicações feministas saem do terreno teórico, encontram fundamentos econômicos; seus adversários fazem-se mais agressivos. Embora os bens de raiz se achem em parte abalados, a burguesia apega-se à velha moral que vê, na solidez da família, a garantia da propriedade privada: exige a presença da mulher no lar tanto mais vigorosamente quanto sua emancipação torna-se uma verdadeira ameaça; mesmo dentro da classe operária, os homens tentaram frear essa libertação, porque as mulheres são encaradas como perigosas concorrentes, habituadas que estavam a trabalhar por salários mais baixos (BEAUVOIR, 1970, p.17).

As colocações de Simone de Beauvoir, podem ser interpretadas de forma que fica claro que ela declara o feminismo como um movimento de massas, além de concordar que a revolução industrial colaborou para que algumas das reinvindicações das mulheres se concretizassem ou deram maior voz a elas. E revela a emancipação das mulheres como uma ameaça à sociedade burguesa. O que justifica o entendimento da opressão sofrida pelas mulheres através do trabalho.

Marx e Engels não aprofundaram muito seus estudos em relação às funções específicas das mulheres na estrutura familiar; por essa razão também há uma dificuldade em 
analisar as disparidades entre a estrutura familiar e a estrutura econômica capitalista e, de acordo com seus estudos, é preciso buscar novas fontes. Dessa forma, buscou-se uma leitura de outros autores como HeleiethSaffioti ${ }^{2}$, uma socióloga marxista e estudiosa da violência de gênero e feminista brasileira, que começou a escrever sobre as condições das mulheres ainda na década de 1960. Ela afirma que o domínio do homem sobre as mulheres não está vinculado diretamente à estrutura econômica da sociedade, acaba influenciando o domínio daqueles que detêm o poder econômico, de certo modo servindo aos seus interesses. No seu artigo $A$ questão da mulher na perspectiva socialista afirma que:

Os homens da classe dominada funcionam, pois, como mediadores no processo de marginalização das mulheres de sua mesma classe da estrutura ocupacional, facilitando a realização dos interesses daqueles que a estrutura de determinação genérica sexo opera como uma cunha no processo de formação da consciência histórica dos homens e das mulheres na medida em que sofram ambos os efeitos da mística feminina (SAFFIOTI, p. 98, 2011).

Ou seja, em outras palavras, ela diz que a submissão dos homens trabalhadores facilita muito a dominação das mulheres pelos que detêm os meios de produção. Por essa razão, torna-se fácil entender porque há um aumento da desigualdade entre homens e mulheres quando há uma diminuição dos direitos em relação a todos os trabalhadores. Ideia que também fica clara nos esclarecimentos de Beavouir. Também cabe reforçar que essa estrutura de produção de bens e serviços e a marginalização do gênero em relação a esse sistema influenciam na estrutura de família em que a mulheres desempenham o que a autora chama de "funções naturais"(2011), entende-se como cuidar dos filhos e dos afazeres domésticos.

HeleiethSaffioti afirma que enquanto a família existiu como um unidade de produção, as mulheres e as crianças desempenharam um papel econômico fundamental (SAFFIOTI, 1976, p. 32). Também lembra que, nas economias pré-capitalistas, a mulher das camadas trabalhadoras era ativa, trabalhava no campo, nas manufaturas, nas minas e nas lojas, entre outras atividades, além de organizar a vida doméstica. A autora ainda afirma que embora a mulher nesse momento encontrava-se inferior às condições do homem, jurídica, social e politicamente seu papel econômico era importante. No entanto, esse trabalho define-se como inferior ao do homem, por tanto, subsidiário, e dessa forma, essa categoria se encarrega pela expulsão da mulher do sistema produtivo (SAFFIOTI, 1976).

\footnotetext{
${ }^{2}$ Informações disponíveis 


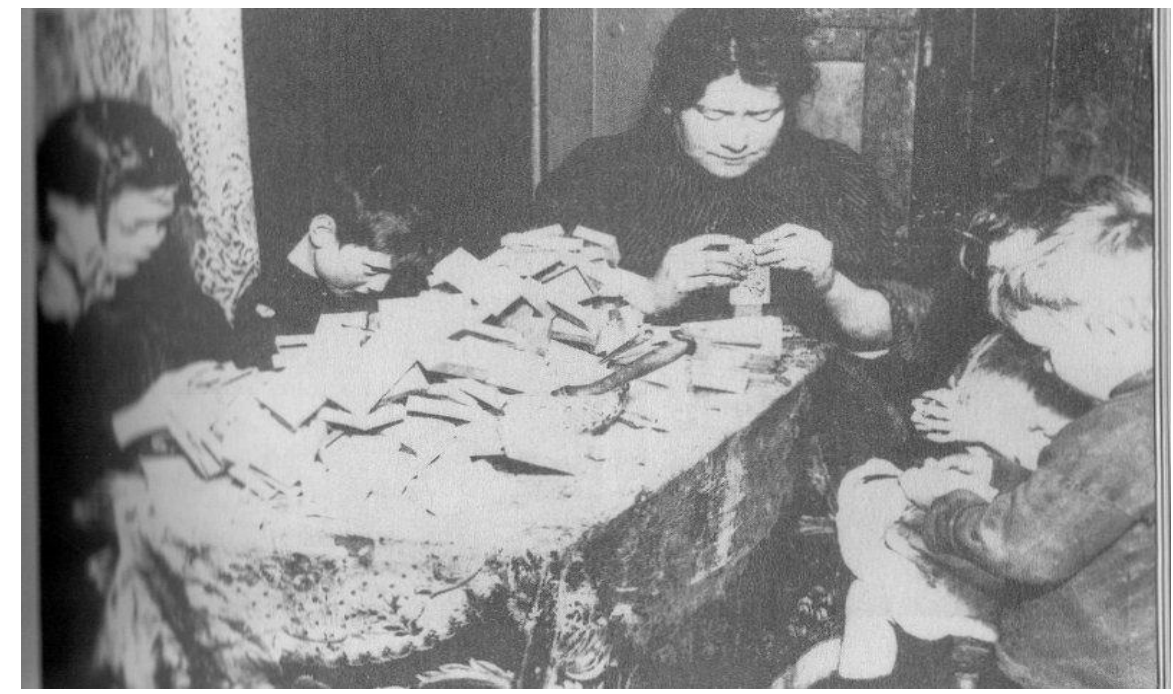

Figura 2. Crianças junto com uma mulher fazendo caixas de fósforo em casa em 1905

Fonte: Eric Hobsbawm, 1989.

O emprego doméstico, remunerado, começa a aparecer pouco antes da Primeira Guerra Mundial, mas esse não inicia com remuneração justa, por muitas vezes essas mulheres, por serem inexperientes, vindas do interior para as grandes cidades, eram superexploradas. Porém, após a guerra, as "criadas" somem e abrem espaço para as faxineiras diaristas, pois nesse momento surgem oportunidades em outras áreas, como em hospitais, fábricas, por exemplo, além de direitos trabalhistas mesmo que incipientes (PERROT, 2017). HeleiethSaffioti vê essa passagem do sistema feudal para o capitalista como uma passagem clara da divisão da sociedade em classes e a exploração econômica de uma pela outra (SAFFIOTI, 1976). As autoras concordam mais uma vez quando HeleiethSaffiotiafirma que a inferiorizarão social da qual as mulheres foram alvos desde séculos contribuiu para a exploração em massa das mulheres no trabalho industrial (SAFFIOTI, 1976).

De fato, os processos de industrialização e transformação dos sistema de produção do feudal para o capitalista colocaram ambos, homem e mulher, em condições subalternas e os afastou da possibilidade da posse dos meios de produção. No entanto, cabe aqui ressaltar que não é negado esse fato, e sim problematizado a forma como as mulheres, em sua condição de gênero feminino, acabaram prejudicadas ainda mais por esse sistema.

O livro, A Revolução das Mulheres: a emancipação feminina na Rússia Soviética, organizado por Graziela Schneider (2017), traz uma coleção de textos escritos no século passado na antiga União Soviética, mas que se mostram ainda muito atuais. Um desses textos é escrito por EkaterinaDmitrievnaKuskova, marxista, feminista e ativista dos movimentos revolucionários liberais e maçônicos. Ela afirma que o sentido da luta das mulheres pela 
igualdade consiste em ter como recompensa por qualquer trabalho desempenhado à sociedade e ao governo, seus plenos direitos, civis e políticos.

\begin{abstract}
Essa é a essência da questão feminina e o sentido da sua luta por igualdade. Entregar à sociedade e ao Estado um trabalho tanto útil quanto genuíno e receber em troca os direitos de que os trabalhadores homens gozam neste país. Eis o objetivo mais imediato de todo o movimento feminino (KUSKOVA, 2017, p. 134).
\end{abstract}

Fica claro ainda que as mulheres sempre estiveram em desvantagem em relação aos homens quando se trata de desenvolvimento das forças produtivas. A sua educação e as formas de exploração do trabalho da mulher contribuíram para que elas se fechassem sem expandir suas ambições, de tal modo que não houvessem interesses além daquele círculo. Kuskova (2017) também traz uma conclusão relevante para este trabalho quando afirma que quanto mais se modificam a vida econômica e íntima da mulher, mais se ampliam suas capacidades e mais se transformam sua mentalidade, dessa forma, manifestando-se em todos os âmbitos da sociedade civil. Afirma também que: "A mulher desperta no trabalho e no serviço público. Ao despertar, torna-se um membro igual nos direitos da família humana que há séculos luta pela igualdade social de todos" (KUSKOVA, 2017, p. 137).

AleksandraMikháilovnaKollontai traz uma reflexão a respeito da mulher trabalhadora na sociedade contemporânea, fazendo um contraponto entre as feministas burguesas e as proletárias. Afirma que as mulheres burguesas possuem acesso fácil às profissões de cunho intelectual, enquanto que às mulheres proletárias só restam as linhas de produção industrial, demonstrando, assim, o quanto é atual este debate. As constatações dessa autora russa servem para ratificar a ideia, presente neste trabalho, de que a discriminação é a nível global, visto que suas experiências pessoais, como ativista comunista, apontam situações em que, não raro, a mulher encontra-se em posição subalterna. Ela afirma, ainda, que "A questão feminina", dizem as feministas, "é questão de 'direito e justiça"'. "A questão feminina", respondem as proletárias, "é questão de um 'pedaço de pão" (KOLLONTAI, 2017, p. 150).

Ela também diz que as proletárias não só foram as primeiras a ingressarem no mundo do trabalho como continuam a reinar nele em termos numéricos. À época, as mulheres eram 5,31 milhões de trabalhadoras industriais e 935 mil burguesas na Áustria, também 5,293 milhões de proletárias e 180 mil mulheres em profissões liberais na Alemanha; e na França, 3,584 milhões de proletárias para apenas 300 mil mulheres da intelligentsia (classe de intelectuais) e assim por diante. Kollontai termina seu texto lembrando que a libertação da 
mulher deve ser a base para a reforma da sociedade, para garantir seu fortalecimento como pessoa e como ser humano (KOLLONTAI, 2017).

\section{Perspectiva feminista}

O feminismo caracteriza-se como um movimento político, social e filosófico que propõe a igualdade entre homens e mulheres em todas as esferas da sociedade. Enquanto movimento político, o feminismo procurou superar as formas de organização tradicionais, permeadas pela assimetria e o autoritarismo (ALVES e PITANGY). Os movimentos se caracterizam por seguirem múltiplas frentes, atuando em diversas questões pertinentes ao feminismo, buscando ampliar o papel das mulheres dentro da sociedade. Com objetivo de transformar a visão do feminino como sendo fraco, desvalorizado e propondo uma reorganização dos modelos hierárquicos, superando a ideia de que as relações entre os sexos são estabelecidas através de relações de poder (feminino x masculino).

Simone de Beauvoir (1970) se consagra como uma autora extremamente importante do feminismo, trazendo questionamentos muito à frente do seu tempo, buscando desconstruir a realidade conservadora em que vivia. Ela busca entender as circunstâncias que restringem a liberdade das mulheres e como superá-las, além também de discorrer sobre como se dá a condição do ser "feminino", abordando pontos de vista da biologia e da psicanálise. No ano de 1949, publicou $O$ Segundo Sexo, sendo esse livro de referência para a formação do feminismo nas configurações que vemos hoje.

Ela afirma que a questão do feminismo em seus primórdios não se tratava de gênero, mas sim estava ligado diretamente às classes. E enfatiza que os interesses de burguesas e proletárias não são os mesmos. As proletárias anseiam a liberdade de todos os trabalhadores, enquanto que as burguesas aderem a novas pautas.

(...) É da emancipação dos trabalhadores em geral que as mulheres esperam a liberdade, não se prendendo senão de um modo secundário à sua própria causa. As burguesas, ao contrário, reclamam novos direitos dentro da sociedade tal qual é, negando serem revolucionárias; querem introduzir reformas virtuosas aos costumes: supressão do alcoolismo, da literatura pornográfica, da prostituição (BEAUVOIR, 1970 p. 159).

No período da Revolução Francesa, as lutas femininas dirigiam-se tanto para as estruturas de Estado e parlamento, na reivindicação dos direitos civis e políticos, quanto para as organizações de trabalhadores. Apesar de as mulheres contarem com o apoio do 
movimento dos trabalhadores na maioria de suas lutas, foi particularmente, com relação ao direito ao trabalho que houve maior resistência. Em 1866, no congresso da Internacional dos Trabalhadores, os delegados foram contrários ao trabalho feminino, o que acabou provocando reação imediata das mulheres socialistas, que intensificaram as manifestações e as petições públicas e fundaram a primeira associação feminista, chamada Liga das Mulheres, em 1868 (GURGEL, 2010, p.2).

O século XIX foi marcado pela luta das mulheres em favor do sufrágio universal, almejado maior envolvimento na vida pública. A luta por liberdade sempre fez parte da história ocidental. A chamada primeira onda ${ }^{3}$ feminista ocorreu a partir das últimas décadas do século XIX, quando as mulheres, primeiro na Inglaterra, organizaram-se para lutar por seus direitos e pelo sufrágio universal, posteriormente nos Estados Unidos. Também ocorrem manifestações semelhantes a esta no Brasil na década de 1930, na qual as mulheres chamadas de "sufragetes" conseguiram conquistar o direito ao voto (PINTO, 2010, p. 15-16).

Eric Hobsbwam (1989) de certa forma legitima essas mudanças em relação ao posicionamento da mulher na sociedade. Ele afirma que, por mais impressionante que seja, historiadores dedicaram atenção ao estudo das mudanças e transformações da mulher na sociedade e também à "emancipação da mulher", embora houvesse um número ainda bem pequeno de mulheres ativas em áreas antes exclusivamente designadas aos homens. Ele destaca, como mudança, o fato de ocorrer uma redução de mulheres com filhos e mais envolvidas na vida pública. Ele também afirma que o voto para as mulheres é um marco para a emancipação e enfatiza o fato de que essa emancipação ocorre para as mulheres da classe média burguesa.

No entanto, enquanto esta nova esquerda socialista (ao contrário das partes antigas e fortemente masculina, radical-democrática e anticlerical esquerda) se sobrepunha com o feminismo sufragista e às vezes se sentia atraída por isso, não podia deixar de observar que a maioria das mulheres da classe trabalhadora trabalhava sob deficiências que eram mais urgentes do que o desrespeito político, que não eram suscetíveis de serem automaticamente eliminadas pelo direito de voto e que não estavam na vanguarda das mentes da maioria dos sufragistas da classe média (HOBSBAWM, 1989, p. 201).

O movimento feminista atual, portanto, pode ser considerado um reflexo das transformações do feminismo original, entendendo-se esse como predominantemente intelectual, branco e de classe média. Ainda nesta primeira onda do feminismo no Brasil, é

\footnotetext{
${ }^{3}$ Houve várias fases no feminismo conhecidas como "ondas feministas". Essas diferentes fases ocorreram em épocas distintas, historicamente construídas conforme as necessidades políticas, o contexto material e social.
} 
interessante voltar atenções para o movimento das operárias de ideologia anarquista, reunidas na "União das Costureiras, Chapeleiras e Classes Anexas". Em manifesto de 1917, proclamam: "Se refletirdes um momento vereis quão dolorida é a situação da mulher nas fábricas, nas oficinas, constantemente, amesquinhadas por seres repelentes" (PINTO, 2003, p. $35)$.

Embora nos sejam mais conhecidas as histórias do feminismo ocidental, encontra-se presente a luta das mulheres também no mundo oriental. Como exemplos citados no capítulo anterior (no livro A Revolução das Mulheres - Emancipação Feminina na Rússia Soviética), as mulheres russas possuem relevância significativa na história das lutas e conquistas das mulheres no mundo todo. Ekaterina D. Kuskova, Ariadna Vladimorovna e Aleksandra M. Kollontia são algumas ativistas da Rússia soviética que marcaram o início do século XX.

Pode-se afirmar que o feminismo trouxe as questões de desigualdade vividas pelas mulheres do privado para o público, com a intenção de denunciá-las. E mais do que isso, com intenção de mudar a realidade das mulheres, em favor da equidade do gênero. Com o processo de "redemocratização" dos países latino-americanos, inicia-se a ampliação dos espaços de participação política e promove-se a ressignificação do conceito de sociedade civil, a partir da década de 1980, quando houve uma forte inciativa dos governos na incorporação da categoria das relações sociais de gênero, como base ou como tema nas políticas públicas (GURGEL, 2010, p.6-7).

\section{Perspectivas feministas nas Relações Internacionais}

As teorias das Relações Internacionais têm a finalidade de formular métodos e conceitos que permitam compreender a natureza e o funcionamento do sistema internacional, bem como explicar os fenômenos mais importantes que moldam a política mundial. Torna-se conhecida a origem da evolução da disciplina de Relações Internacionais do período imediatamente posterior à tragédia da Primeira Guerra Mundial - e nos rastros de destruição que ela havia deixado. A disciplina surge, portanto, com o objetivo de estudar as questões relevantes em relação à guerra, mais precisamente, com a finalidade de livrar a humanidade de consequências perversas e, para o fim de evitar a repetição de tragédias semelhantes às da chamada Grande Guerra (NOGUEIRA e MESSARI, 2005).

Como uma perspectiva nova para a disciplina, o feminismo aparece, inicialmente, como um movimento característico das mulheres burguesas. $\mathrm{Na}$ década de 1920, os movimentos assumiam características de reinvindicações que eram pautadas apenas pelas 
necessidades da burguesia, como por exemplo, direito a voto. Dessa forma, passou-se a perceber que o próprio movimento vinha sendo excludente, pois enquanto as reivindicações da burguesia eram pautadas por direitos legais, muitas mulheres ainda continuavam subjugadas e permaneciam sendo exploradas, especialmente as mulheres pobres e negras, havendo então uma necessidade de se reverem as pautas desses movimentos, de forma que passassem a trazer também as necessidades básicas às mulheres. ${ }^{4}$

Nesse contexto, surge na disciplina de Relações Internacionais, no final do século XX, uma perspectiva alternativa, a fim de quebrar este ciclo de poder exclusivamente masculino, trazendo as questões de gênero como uma categoria empírica relevante para análise e entendimento das relações de poder global, bem como uma posição normativa a qual constrói alternativas para a ordem mundial (TRUE, 2005).

A autora JacquiTrue(2005) divide o feminismo em três categorias: feminismo empírico, feminismo analítico e feminismo normativo. A primeira categoria avalia que o feminismo empírico busca demonstrar que há uma negação ou deturpação das mulheres na política mundial pelo falso pressuposto de que as experiências masculinas podem contar por ambos e que ainda, as mulheres são ausentes nas relações internacionais e irrelevantes para os processos globais. A segunda categoria afirma que "o feminismo analítico descontruiu a estrutura teórica das relações internacionais, revelando o viés de gênero que permeia os conceitos-chave e inibe uma compreensão precisa e abrangente das relações internacionais". A terceira categoria questiona a construção binária de gênero.

Há variadas vertentes dentro da perspectiva feminista, cada umas dessas vertentes nos dá visões diferentes em relação à subordinação das mulheres. Tais abordagens incluem o feminismo liberal, marxista, socialista, pós-colonialista e o pós-moderno. O feminismo liberal acredita que removendo os obstáculos legais é possível superar a subordinação das mulheres. No entanto, em outras abordagens como a pós-liberal, a subordinação ao patriarcado,a qual não pode ser superada de forma isolada, está enraizada na sociedade. O pós-colonialismo e o pós-modernismo acreditam que não podemos generalizar a opressão sofrida pelas mulheres. A subordinação das mesmas se dá em classes e espaços geográficos diferentes (TICKNER, 1992). O feminismo marxista busca justamente investigar e explicar as formas pelas quais as mulheres são oprimidas dentro do sistema capitalista e da estrutura de propriedade privada. A perspectiva do feminismo nas RI, trata do problema de gênero em prol da luta do proletariado

\footnotetext{
${ }^{4}$ She's beautiful when she's angry. Direção: Mary Dore. Produção: Mary Dore, Nancy Kennedy. Estados Unidos, 2014. 92 min. Legendado. Color, steorosound.
} 
contra o sistema capitalista, trazendo a mulher para o cerne da questão e, portanto, colocandoa em posição de oradora e não somente de ouvinte.

O debate do feminismo dentro da disciplina de Relações Internacionais ainda é muito modesto. Nogueira e Messari (2005), por exemplo, não ampliam muito suas abordagens sobre feminismo, reservando apenas um espaço a esse tema junto com o pós-colonialismo, no último capítulo de seu livro. E o fato de reservarem meio capítulo ao feminismo demonstra que deram mais destaque a esse assunto em detrimento às teorias ditas normativas. Ainda assim, demonstrando dessa forma como a importância empregada a esses debates ainda é precária. Essa perspectiva traz para as relações internacionais, portanto, os debates relevantes às discussões sobre gênero, mais especificamente questões relevantes à identidade. Dentro da disciplina, por exemplo, a discussão se dá no âmbito de quem escreve, o que escreve, o que lê e pra quem escreve.

Justamente pelo fato de as Relações Internacionais serem um campo que dedica pouco espaço às mulheres, há certa dificuldade em encontrarmos autoras da disciplina, portanto, tomo emprestadas as palavras de Simone de Beauvoir, que no livro O Segundo Sexo esclarece exatamente o que está sendo proposto demonstrar aqui:

The representation of the world, like the world itself, is the work of men; they describe it from their own point of view, which they confuse with absolute truth" (BEAUVOIR, 1949, p.196). ${ }^{5}$

True(2005) concorda com essa colocação na medida em que afirma que um dos principais objetivos do feminismo é expor a exclusão das mulheres do discurso teórico das Relações Internacionais, pois trata de tentar expor a construção sexista e androcêntrica das RI, e em seguida tenta introduzir essa visão na disciplina. Levar em conta uma visão feminina significa reconhecer seriamente as experiências de, ao menos, $50 \%$ da população mundial. Ou seja, não é possível aceitar que o discurso masculino seja aquele que represente tanto os homens quanto as mulheres. Assim, levar em conta as mulheres abre novas perspectivas para as Relações Internacionais, envolvendo novos tópicos de investigação, como a vida diária das mulheres, sua luta contra a opressão, seu papel nas transformações sociais (TRUE, 2005).

Poderia interpretar as palavras de Heleieth para explicar essa escassez da presença feminina na disciplina, pois, conforme a autora, a ideia de que a missão da mulher é o

\footnotetext{
${ }^{5}$ A representação do mundo, como o próprio mundo, é obra dos homens; eles o descrevem a partir de seu próprio ponto de vista, o que eles confundem com a verdade absoluta. (Tradução livre).
} 
casamento e a reprodução a colocou em condição subalterna em ocupações mal remuneradas e sem perspectiva. As famílias proletárias, portanto, designam as mulheres à condição de dona de casa, guardiã do lar, como coloca a autora, e dessa forma, as próprias mulheres assumem esse dado como destino social determinado pelo sexo (SAFFIOTI,1976). E, por essa razão, as colocam em uma posição em que pouco podem exigir em relação à remuneração e condições de trabalho, dessa forma, elas mesmas acabam subestimando sua capacidade e deixam de ter maiores ambições, o que explicaria porque elas não têm acesso a essa área, criada por homens, para homens.

As abordagens que usam o gênero como categoria de análise no estudo das relações internacionais buscam explicações para a assimetria nas relações entre os gêneros e constituição de identidades de homens e de mulheres. Dessa forma, as abordagens feministas possuem em comum o fato de incluírem uma dimensão política, não apenas de superação da opressão feminina, mas também de construção de uma ordem internacional mais justa, na qual hierarquias de gênero, classe ou raça, não façam parte dessa ordem.

O movimento feminista havia passado por duas etapas, ambas internas ao Estado, antes de chegar ao estudo das relações internacionais. Como já mencionado, na primeira etapa lutou-se pelo sufrágio universal e pela inclusão das mulheres no espaço político, enquanto a segunda ocupou-se de uma agenda de inclusão social e cidadania. Essas duas primeiras etapas eram penetradas no Ocidente e, consequentemente, sua agenda refletia a agenda do movimento feminista ocidental. $\mathrm{O}$ que não significa que mulheres de fora do Ocidente não defendiam a mesma agenda ou que não existia um movimento feminista fora do Ocidente. No entanto, significa que o feminismo era dominado por uma agenda ocidental. A terceira etapa passou a envolver feministas na disciplina de Relações Internacionais e também tem sido menos centrada no Ocidente e mais inclusiva na sua agenda.

A construção política dos gêneros implica em uma supervalorização do masculino e de suas atividades e resulta em uma organização da atividade social e política de forma hierarquizada, fazendo com que identidades e atividades que são concebidas como próprias dos homens, ou de características masculinas, tenham maior prestígio em relação às identidades e atividades associadas às mulheres ou a características tidas como femininas. Essa hierarquização é uma construção política, na medida em que distribui poder, autoridade e recursos de forma a privilegiar os homens. Limitar o acesso das mulheres aos recursos, ao poder e à autoridade torna-se, portanto, desigual e desprivilegiado. 
Tickner (1992), por exemplo, observa e critica a escassa presença de mulheres não apenas como atores políticos relevantes na política internacional, mas também como acadêmicas da área, sobretudo no que tange a questões de guerra e paz, sendo essa a área mais central e politicamente atuante da disciplina. Essa assimetria dentro das Relações Internacionais, como campo político e como disciplina, é um prognóstico de relações de poder desiguais entre gêneros, cujo alcance social é muito mais amplo e profundo do que as soluções propostas pelo feminismo liberal são capazes de abordar.

Nesse sentindo, entram em discussão, portanto, questões sobre a construção social e política das representações de gênero, sobre por quem elas são reproduzidas e sobre como elas são sustentadas, concluindo uma dimensão crítica de emancipação. Sendo assim, parte significativa da corrente feminista da disciplina se distancia da suposição feminista liberal clássica (essa que se ocupa em resolver desigualdades de gênero através de medidas exclusivamente políticas e/ou legais) para refletir sobre como o não lugar das mulheres se associa a um imaginário político de gênero social e historicamente construído: o masculino como forte, poderoso, autônomo e racional; o feminino como fraco, ingênuo, incapaz (TICKNER, 1992).

A partir desses questionamentos, abrem-se discussões sobre o que é considerado objeto de estudo pela disciplina e sobre que forma de ciência é concebida como legítima para estudá-las, ou seja, debates e reflexões sobre como a disciplina das Relações Internacionais é construída, e como ela deve se reconstruir. Conforme proposto por Tickner:

Ignoring women's experiences contributes not only to their exclusion but also to a process of self-selection those results in an overwhelmingly male population both in the foreign policy world and in the academic field of international relations (TICKNER, 1992, p. 4). ${ }^{6}$

Assim, de acordo com o ponto de vista feminista, a identidade de gênero desempenha uma função determinante no pensamento de uma sociedade. A inclusão de questões de gênero, como uma categoria de análise, tem o potencial de transformar os resultados políticos de uma atividade hoje dominada por um único gênero.

Outra forma de feminismo que podemos destacar, caracteriza-se por uma grande influência da Teoria crítica. Essa forma que o feminismo adota descreve-se pela busca de emancipação, ao mesmo tempo em que oferece uma maneira alternativa de pensar algo que não faz parte da agenda das feministas pós-modernas. Por fim, algumas feministas passaram a

\footnotetext{
${ }^{6}$ Ignorar as experiências das mulheres contribui não só para a sua exclusão, mas também para um processo de autos seleção que resulta numa população predominantemente masculina tanto no mundo da política externa como no domínio acadêmico das relações internacionais. (Tradução própria).
} 
estabelecer elos com o construtivismo, uma vez que o construtivismo providencia recursos analíticos úteis ao feminismo, como os debates sobre identidades e instituições. As ligações são mais do que disponíveis; são naturais, já que, no centro do feminismo, existe o conceito da construção social, onde o gênero não é natural nem predeterminado, mas sim socialmente construído.

Dentro da ampla diversidade de feministas, há uma preocupação comum em relação à construção do gênero. Nogueira e Messari (2005) propõem que todas as correntes feministas desafiam as teorias de Relações Internacionais no que se refere à sua suposta natureza neutra em relação ao gênero. Fazem isso mostrando como premissas sobre papéis e conhecimento são marcadas pela questão de gênero e insistem no fato de que a disciplina é mais "cega" em relação ao gênero que "neutra" em relação a ele. Aliás, a própria questão do gênero vem a ser relevante aqui. Quando as feministas começaram a falar de gênero em vez de sexo, operaram duas transformações. Por um lado, questionaram a naturalidade biológica do sexo. Quando se fala em sexo, se fala em biologia, e não em relações sociais e de poder. Quando se fala em gênero, se fala de uma construção social que define a masculinidade e a feminidade.

As manifestações teóricas que até a pouco tiveram lugar, expulsaram as mulheres das construções teóricas de RI, uma vez que as mulheres foram suprimidas da teoria, a perspectiva feminista aparece com o objetivo de desestabilizar e subverter o campo, por meio de vozes femininas e formas femininas de conhecer para ampliar o espaço ontológico da disciplina. Com isso, procurou-se demostrar a possibilidade de uma convergência entre preocupações feministas e uma teoria de RI, que seja capaz de mostrar as formas pelas quais as mulheres são inevitavelmente parte do campo, além de uma categoria útil à análise de diversos fenômenos internacionais, ainda que tenhamos nos dado conta disso apenas recentemente.

\section{Relatórios anuais ONU Mulheres (2010-2016) e Relatório sobre mulheres no mundo do trabalho OIT (2016)}

Comparando-se a dados mais atuais cabe aqui analisar os relatórios produzidos anualmente pela ONU Mulheres e também pela OIT trazendo dados a respeito desse tema. A ONU Mulheres é uma organização dedicada à igualdade de gênero e ao empoderamento das mulheres, promovendo uma campanha global para mulheres e meninas.

A ONU Mulheres define o conceito de emancipação das mulheres pautado pela autonomia econômica. A entidade acredita que ao promover a equidade de gênero em todas as 
atividades sociais e econômicas, estará garantindo efetivamente o fortalecimento das economias, ao impulsionar os negócios e a melhoria da qualidade de vida das mulheres, além de desenvolvimento sustentável. A entidade diz estar a par do papel das empresas para o crescimento das economias e para o desenvolvimento humano. Com isso, essa entidade, junto com o Pacto Global ${ }^{7}$, criaram osPrincípios de Empoderamento das Mulheres, que são um conjunto de considerações que ajudam a comunidade empresarial a incorporar em seus negócios valores e práticas que visem à equidade de gênero e o empoderamento feminino.

A entidade anualmente divulga relatórios a respeito do que diz que têm se proposto a fazer para superar a discriminação de gênero no mundo. Esses relatórios são elaborados e divulgados em períodos distintos. A assistência da entidade foca em dar suporte à liderança das mulheres, empoderamento econômico, fim da violência contra as mulheres, promover a participação delas nos processos de paz e segurança, e assegurar que o planejamento público corresponda às necessidades e direitos das mulheres. Alguns dos relatórios trazem dados acerca da desigualdade em nível global, portanto, cabe aqui ressaltar a importância dessa análise.

A entidade possui um plano de ação para o desenvolvimento sustentável no mundo, no qual são descritos 17 objetivos, chamada de "Agenda 2030 para o desenvolvimento sustentável da ONU. No quadro a seguir, é contemplado empoderamento econômico, pautado pelos objetivos que buscam maior acesso das mulheres a terras e recursos de produção para o clima e agricultura: estímulo a oportunidades iguais para mulheres empresárias através de aquisições afirmativas, investimento e suprimento à cadeia de políticas; segurança de uma renda decente através de proteção social e do trabalho para mulheres; energia sustentável para as mulheres e acesso ao empreendedorismo.

\footnotetext{
${ }^{7}$ O Pacto Global é uma iniciativa desenvolvida pelo ex-secretário-geral da ONU, Kofi Annan, com o objetivo de mobilizar a comunidade empresarial internacional para a adoção, em suas práticas de negócios, de valores fundamentais e internacionalmente aceitos nas áreas de direitos humanos, relações de trabalho, meio ambiente e combate à corrupção, refletidos em 10 princípios. Essa iniciativa conta com a participação de agências das Nações Unidas, empresas, sindicatos, organizações não-governamentais e demais parceiros necessários para a construção de um mercado global mais inclusivo e igualitário. Hoje já são mais de 12 mil organizações signatárias articuladas por cerca de 150 redes ao redor do mundo.
} 


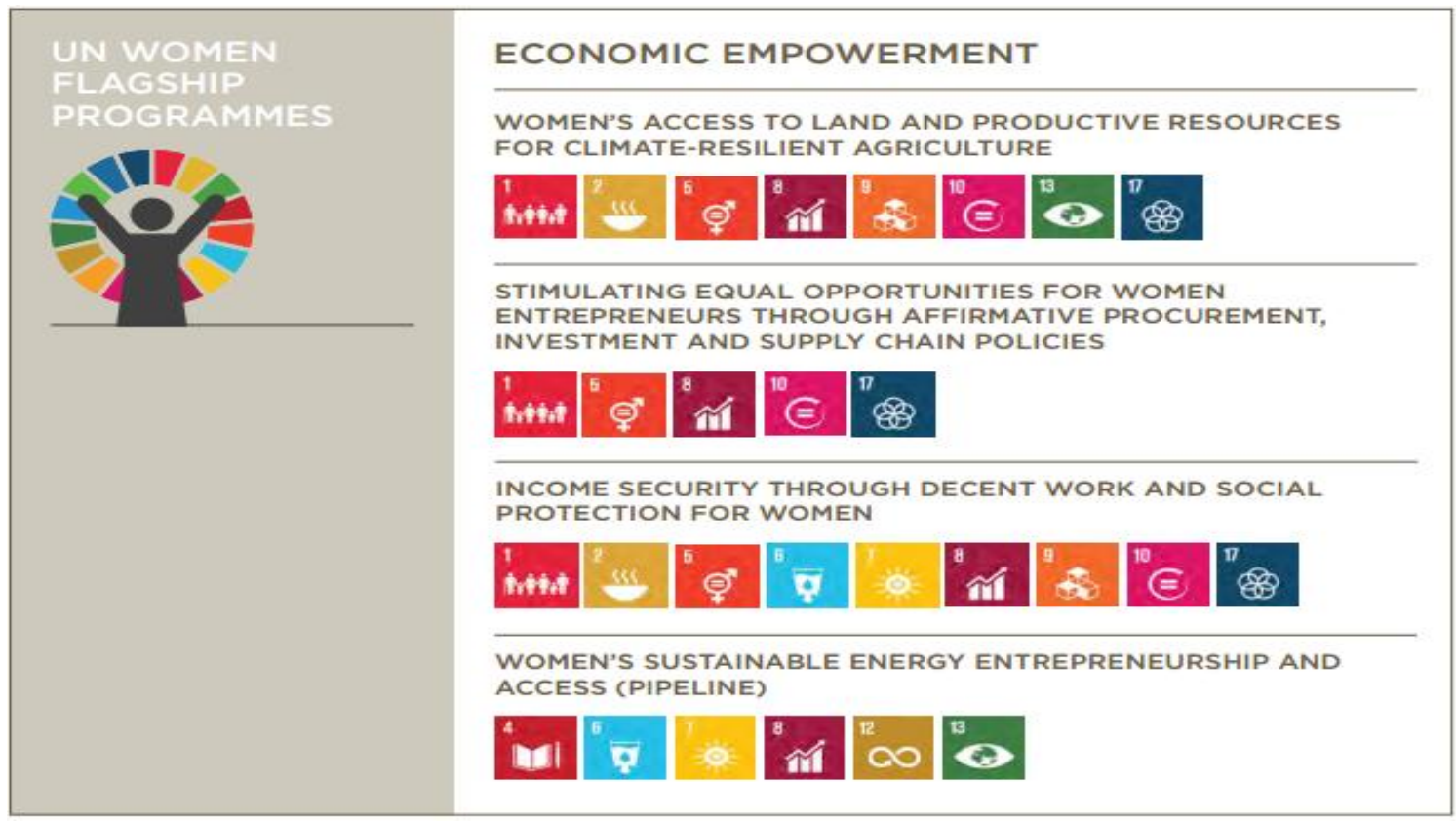

Figura 3. Empoderamento econômico.

Fonte: UN Womenannualreport (2015-2016).

É possível perceber que as taxas de participação das mulheres no campo de trabalho no mundo ainda são pequenas e a evolução dentro do período de 20 anos ocorreu de forma muito lenta, como fica claro na figura a baixo:

\section{Disparidades de gênero nas taxas de participação da força de trabalho por região, 1995 e 2015}

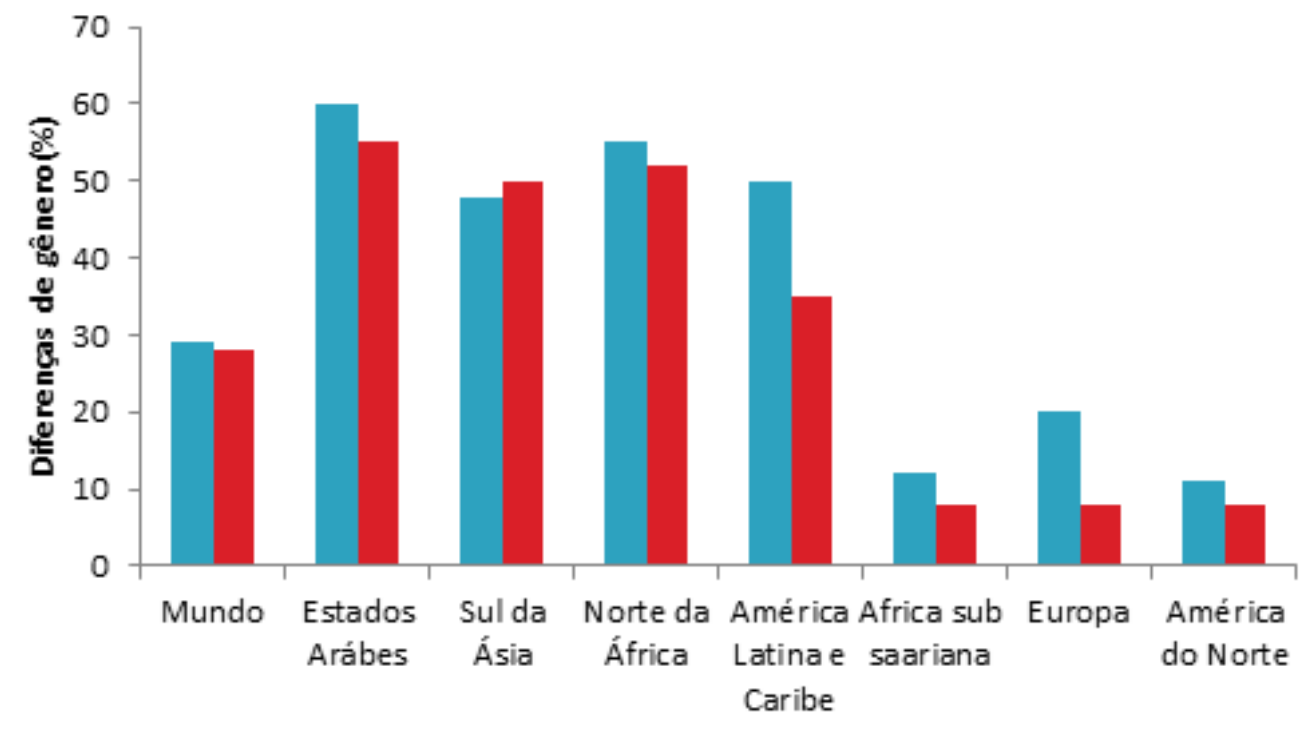


Figura 4 .Índice medido em \%, com base em dados de 178 países, o gráfico original consta no relatório da OIT WomenatWork - Trends 2016. Foi editado para facilitar a visualização, cobrindo apenas as principais regiões de interesse nessa pesquisa. Taxa aproximada do gráfico original.

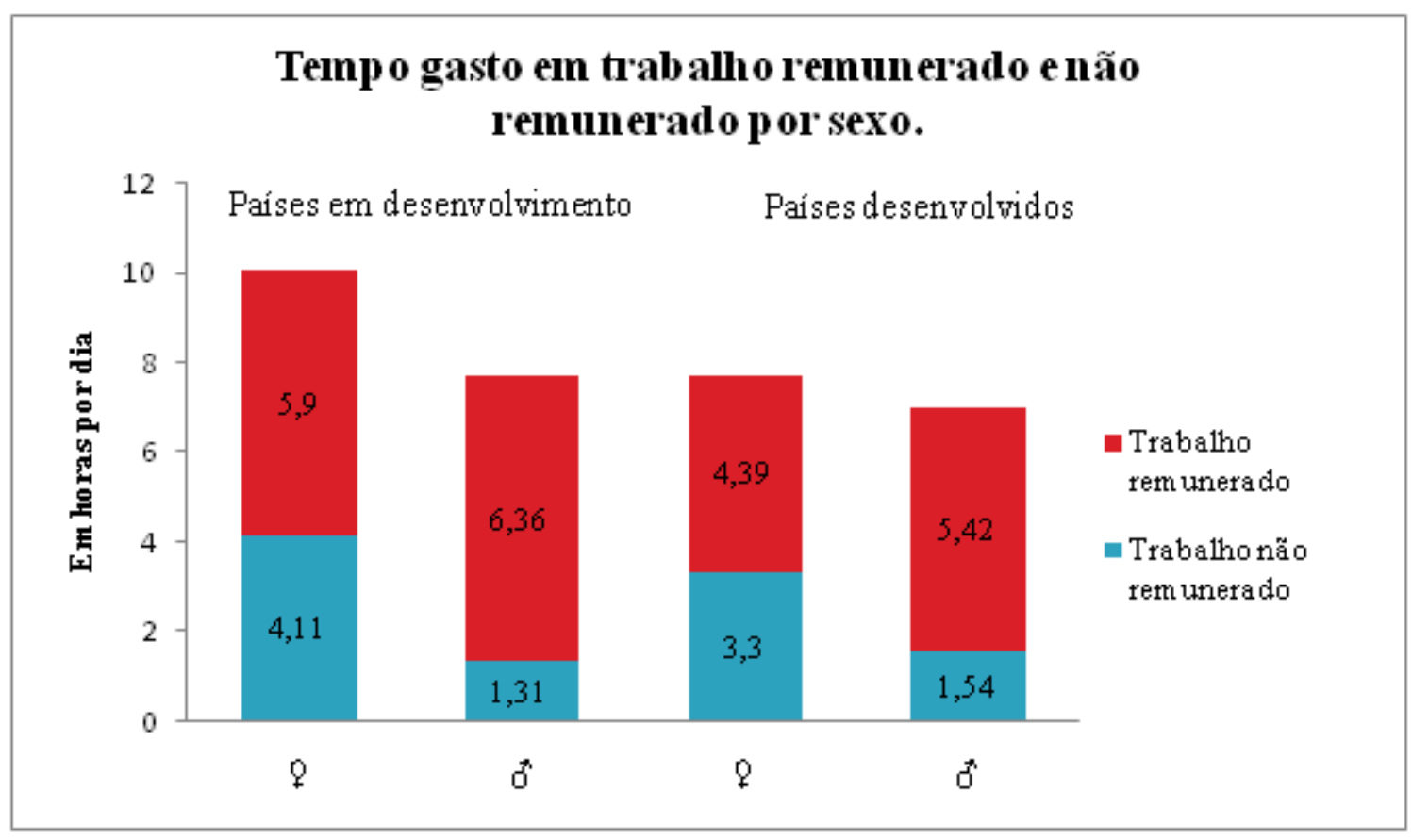

Figura 5.Gráfico produzido a partir de dados de 23 países desenvolvidos e 23 em desenvolvimento. Dados extraídos do relatório Womenatwork - Trends 2016.

Ambos os gráficos nos mostram como a disparidade entre homens e mulheres continua sendo grande. Os números se distanciam ainda mais quando comparamosos dados de países desenvolvidos com os dos países em desenvolvimento, ou seja, a desigualdade mostra-se ainda maior nessas regiões menos desenvolvidas economicamente. A figura 3 mostra que o índice de mulheres desempregadas fica em torno de 6,2\% enquanto que para homens, esse índice fica em 5.5\%. ${ }^{8} \mathrm{Na}$ figura 2, fica evidente as disparidades em relação ao trabalho remunerado e o trabalho não remunerado, nos países em desenvolvimento e depois nos países desenvolvidos. Podemos concluir que as mulheres trabalham em torno de 2,8 horas a mais que os homens nos trabalhos domésticos (não remunerados) nos países em desenvolvimento e, 1,76 horas a mais nos países desenvolvidos.

\footnotetext{
${ }^{8}$ Dados da Organização Internacional do Trabalho de 2016.
} 


\section{Diferença salarial entre licença maternidade em países selecionados (último ano disponível, salários não ajustados)}

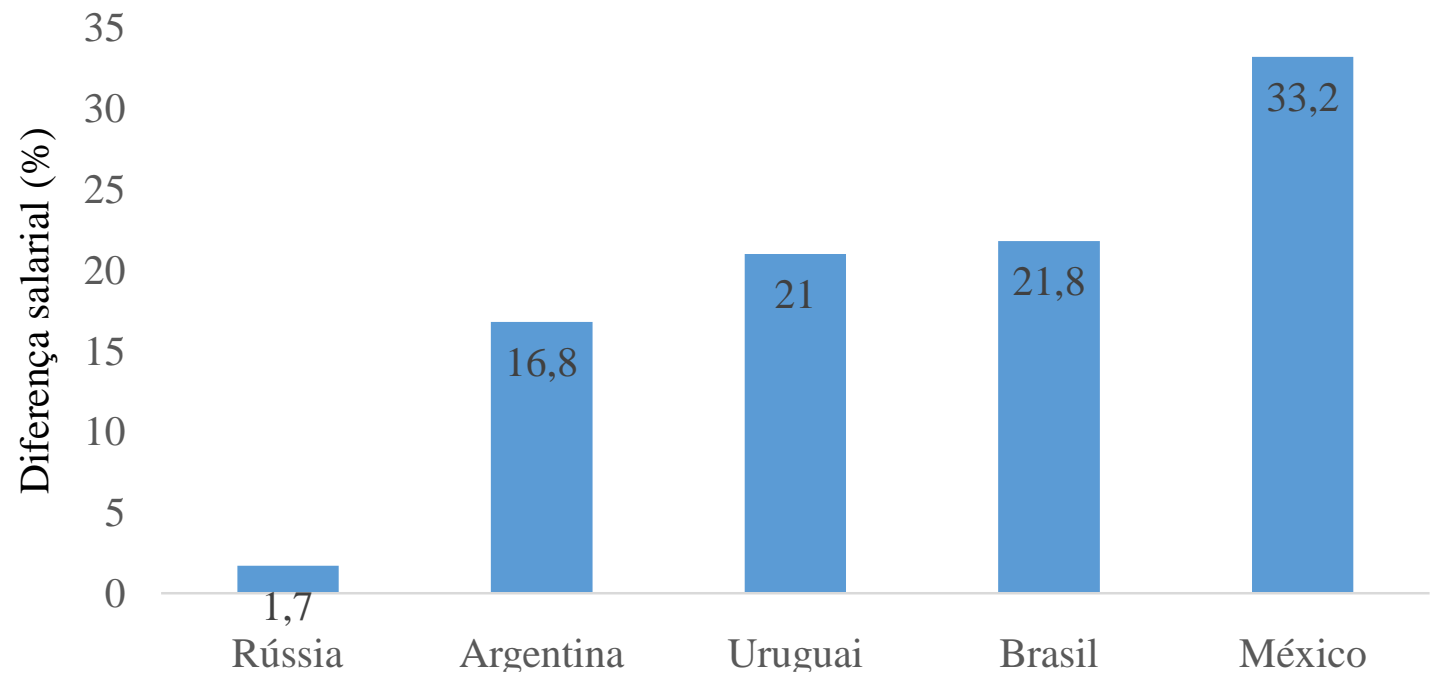

Figura 5 .Índice em \%, diferença salarial no período da licença maternidade em 5 países distintos.

O gráfico 3 propõe demonstrar como as taxas de diferença salarial são bastante elevadas durante o tempo de licença maternidade, sendo esse um direito de toda gestante, acentuando ainda mais a desigualdade enfrentada pelas mulheres no campo de trabalho, especialmente em um momento que é tão importante para as mulheres o auxílio financeiro que a licença proporciona. Por exemplo, no México a variação passa dos 30\%, o que é alarmante.

A OIT afirma que as mulheres continuam enfrentando obstáculos significativos de acesso a empregos dignos em sua vida profissional ao longo dos anos, e também afirma que os progressos alcançados até agora foram marginais, deixando uma grande lacuna a ser abordada pela Agenda 2030 para o Desenvolvimento Sustentável adotada em 2015.

A desigualdade entre homens e mulheres persiste nos mercados de trabalho globais, em relação às oportunidades, ao tratamento e aos resultados. Nas últimas duas décadas, os significativos progressos alcançados pelas mulheres na educação não se traduziram numa melhoria comparativa na sua situação no trabalho. Em muitas regiões do mundo, as mulheres, comparativamente aos homens, têm mais probabilidades de permanecerem ou virem a ficar desempregadas, têm menos oportunidades de participar no mercado de trabalho e - quando o conseguem - muitas vezes têm de aceitar empregos de qualidade inferior (OIT, 2015).

O que se conclui é que as entidades como OIT e ONU Mulheres têm estado atentas às questões pertinentes à diferenças entre homens e mulheres no mercado de trabalho. Porém é 
preciso fazer mais, é preciso maior empenho dos próprios países para que essas diferenças comecem a diminuir substancialmente e não de forma marginal como ocorreram nos últimos 20 anos de que se obtém registro, desde que as entidades começaram a medir essas diferenças.

Portanto, ficou claro até aqui que os dados apresentados pelas entidades convergem com o que foi exposto nos capítulos anteriores em relação às teorias. Por mais que as abordagens das entidades não possuam características necessariamente ideológicas, elas só confirmam a dimensão do problema, sendo ele reconhecido por duas entidades de alcance internacional, como a OIT e a ONU Mulheres, que mostram dados de diversos países, tanto desenvolvidos quanto os em desenvolvimento. Também propõem medidas, como proteção aos trabalhadores e leis e normas internacionais que buscam diminuir essas diferenças, com o propósito de trazer maior autonomia econômica para os trabalhadores, em especial, às mulheres.

\section{Considerações finais}

Ao longo deste trabalho, procurou-se demonstrar o papel das mulheres no mundo do trabalho e de que forma elas são discriminadas nessa área em função do seu gênero. Também procurou-se apresentar as abordagens a respeito do feminismo que as Relações Internacionais trazem e a forma como essa área de estudo trata a presença e a relevância das mulheres no mundo do trabalho. Ao abordar textos de autores de diferentes países, observa-se que o problema de discriminação é comum a todos e há muito vem sendo debatido. Portanto, a ênfase que se buscou atribuir tem como foco o fato de esse ser um problema atual e que acontece em âmbito global.

A disciplina de Relações Internacionais ganhou destaque a partir da década de 1990 e, a princípio, possuía uma visão mais focada no Estado, não abordando as questões feministas, por exemplo, apenas dando espaço às teorias tradicionais. Portanto, cabe aos novos estudantes da área trazerem, questões tão pertinentes ao desenvolvimento da própria sociedade como um todo, evidenciando como as mulheres são parte importante do desenvolvimento da sociedade atual, sem esquecer-se-também de sua relevância para a história da própria humanidade.

No primeiro momento foram apresentados dados a respeito de como se deu a história das mulheres no mundo do trabalho. E embora a amostra dos dados não seja extensa, é suficiente para deixar claro que as lutas feministas sempre tiveram presentes na história da humanidade, assim como os esforços pelo reconhecimento dos trabalhos desenvolvidos pelas mulheres. A exemplo disso, tem-se a Revolução Francesa como um marco tanto para a 
história da humanidade como um todo, como para a contribuição das mulheres no desenvolvimento delas no mundo do trabalho.

Ainda nesse primeiro momento, em que se tratou sobre as mulheres no mundo do trabalho, foram abordadas as perspectivas de alguns autores, entre eles, Michelle Perrot, Simone de Beauvoir e Eric Hobsbawm. Foi apresentado o panorama desses autores sobre a construção da história das mulheres, em particular das mulheres trabalhadoras, que, por sua vez, conforme evidenciam os autores, sempre trabalharam muito mais, seja no campo ou nos cuidados de casa. De fato, o sistema como vemos hoje, estabelece condições desiguais para as mulheres, colaborando para que haja essa dupla exploração delas.

No segundo momento, tratou-se da perspectiva feminista, de como surgiu, afirmou-se, portanto, que o Feminismo se caracteriza como um movimento político, social e filosófico que propõe a igualdade entre homens e mulheres em todas as esferas da sociedade. As mulheres encontram-se presentes em todo o processo de consolidação da sociedade moderna, elas mantiveram-se na resistência e por essa razão foram consideradas uma ameaça para a burguesia. Viu-se também como o direito ao voto mobilizou as mulheres no mundo todo, as sufragetes ou sufragistas como ficaram conhecidas, protagonizaram os movimentos sociais das mulheres em prol dos direitos políticos.

Posteriormente a isso, buscou-se demonstrar como a perspectiva feminista dentro da disciplina de Relações Internacionais aparece muito tardiamente, somente a partir da década de 1980, surgem as primeiras abordagens sobre o tema. J. Ann Tickner mostra-se como a primeira mulher a tratar do tema dentro da esfera das Relações Internacionais, justamente questionando essa escassez de mulheres na área, que é predominantemente masculina. Essa perspectiva alternativa busca quebrar o ciclo de poder exclusivamente masculino, trazendo as questões de gênero como uma categoria empírica relevante para análise e entendimento das relações de poder no mundo. Também demonstraram-se dados a respeito da participação das no trabalho mundo, no sentido de fazer uma pequena comparação com dados mais atuais, dados esses extraídos de relatórios da ONU Mulheres e também da OIT.

Buscou-se discutir sobre a discriminação enfrentada por mulheres no âmbito do trabalho e observou-se que essa questão é muito mais ampla e abrange outras esferas que envolvem a disparidade de gêneros. O que se obteve aqui foi o resultado de um filtro de alguns dos problemas de gênero que vêm sendo discutidos há alguns anos. Como aluna de Relações Internacionais, é importante e interessante abordar essa temática para que essas questões referentes às mulheres ganhem espaço dentro da disciplina e, mais do que isso, é 
importante mostrar que as mulheres, cada vez mais, possuem voz ativa e buscam ser ouvidas dentro dessa área que é majoritariamente masculina.

Portanto, fica claro até aqui como a discriminação das mulheres é um problema que existe no mundo, e não está exclusivamente ligado apenas a um lugar. Também fica evidente que o papel das mulheres na história das lutas, tanto pelos seus direitos como pelos direitos de todos os trabalhadores, no geral, fizeram e ainda fazem diferença, de modo que ainda refletem na maneira como é buscada a equidade dos gêneros. Seja através de esferas interacionais como a ONU Mulheres, por meio dosPrincípios de Empoderamento das Mulheres, por exemplo, que visem à equidade de gênero e o empoderamento das mulheres, seja por meio de debates através de disciplinas acadêmicas como as RI. Dessa forma, fica clara a ligação entre as teorias apresentadas nos capítulos anteriores, bem como a observação de que o que foi dito permanece atual, não só na história dos trabalhadores no geral, mas na história das mulheres como um todo.

Concluiu-se, portanto, que as mulheres são discriminadas no campo de trabalho até hoje e que esse é um problema global. De fato, apesar de ocorrer de formas diferentes em outros lugares do mundo, essa desigualdade está presente e não tem mostrado grandes avanços no sentido de ser modificada. Ficou claro que esse é um problema sistêmico, no sentido que o sistema capitalista só contribui para a desigualdade tal qual vemos hoje. Contudo, apesar de as mulheres terem ganhado espaço relativamente considerável, ainda há muito que evoluir para melhorar as condições das mulheres no mercado de trabalho, em especial no campo de Relações Internacionais. É preciso criar medidas ativas e contundentes de políticas inclusivas que estimulem a exploração dessa área que vem crescendo e demonstrando cada vez mais relevância no mundo, desde o século passado.

\section{Referências bibliográficas}

ALVES; PITANGUY. O que é feminismo? - Coleção primeiros passos.Abril Cultura/ Brasiliense, 1982.

ANDERSON, Perry. Considerações sobre o marxismo ocidental. 2 ed. São Paulo: Brasiliense, 1999.

BEAUVOIR, Simone de. O Segundo Sexo - Fatos e Mitos. Vol. Ed. 4. São Paulo: Difusão Europeia do Livro, 1970.

BURCHILL; LINKLATER, et al.Theories of International Relations. $3^{\text {a }}$ edição. New York Palgrave Macmillam, 2005. 
DUARTE, Angelica da Silva; CHERFEM, Carolina Orquiza. Programa Pró-equidade de gênero e raça: Rompendo fronteiras no mundo do trabalho. Secretaria Especial de Políticas para as mulheres. Brasília, 2016.

ENGELS, Friedrich. A Origem da Família, da Propriedade Privada e do Estado. 3.ed. São Paulo: Escala, 2009.

FREEDMAN, Jane. Feminism - Concepts and the social sciences. Philadelphia: Open University Press, 2001.

GURGEL, Telma. Feminismo e luta de classe: história, movimento e desafios teóricopolítico do feminismo na contemporaneidade. Fazendo Gênero: Diásporas, diversidade, deslocamentos. Santa Catarina, n. 9, ago. 2010. Disponível em: $<$ http://www.mulheresprogressistas.org/AudioVideo/FEMINISMO\%20E\%20LUTA\%20DE \%20CLASSE.pdf> Acesso em: 16 Junho 2017.

HOBSBAWM, Eric. The Age of Empire (1875 - 1914). New York: Vintage Books ed, 1989.

ILO, International Labour Organization. Womens at Work Trends 2016. Geneva: internatio nal labour office, 2016.

JACKSON, Robert e SORENSEN, Georg. Introdução às Relações Internacionais. Rio de Janeiro, Zahar Editora, 2007.

LENIN, V. I. O Socialismo e a Emancipação da Mulher. Rio de Janeiro: Editora Vitória, 1956.

MARX, Karl e ENGELS, Friedrich. Manifesto do Partido Comunista (1848). São Paulo: L\&PM Pocket, vol. 227, 2001.

NARVAZ, KOLLER. Metodologias feministas e estudos de Gênero: Articulando pesquisa, clínica e política. Psicologia em Estudo, Maringá. v. 11, n. 3, p. 647-654, 2006.

NOBRE, Miriam; CAREGATTI, Alessandra. Gênero e Autonomia Econômica para as Mulheres. Secretaria Especial de Política para as Mulheres. Brasília, 2016.

NOGUEIRA, João Pontes; MESSARI, Nizar. Teoria das Relações Internacionais Correntes e Debates. Rio de Janeiro: Elsevier, 2005.

PERROT, Michelle. Minha história das mulheres. 2 ed. São Paulo: Contexto, 2017.

PINTO, Céli Regina Jardim. Feminismo, História e Poder. Revista de Sociologia e Política. 18 vol, no $36: 15-23,2010$.

SAFFIOTI, Heleith. A questão da mulher na perspectiva socialista. Lutas Sociais, São Paulo, n.27, p.82-100, 2o sem. 2011. Disponível em <http://www4.pucsp.br/neils/downloads/07-heleieth-saffioti.pdf> Acesso em 17 Maio 2017. 
SARFATI, Gilberto. Teorias de Relações Internacionais. São Paulo: editoraSaraiva, 2005.

SHE'S, beautiful when she's angry. Direção: Mary Dore. Produção: Mary Dore, Nancy Kennedy. Estados Unidos, 2014. 92 min. Legendado. Color, stereo sound.

SHNEIDER, Graziela (Org.). A Revolução das Mulheres - Emancipação Feminina na Rússia Soviética: artigos, atas, panfletos, ensaios. São Paulo: Boitempo, 2017.

TEIXEIRA, Cíntia Maria. As Mulheres no Mundo do Trabalho: Ação das Mulheres, no Setor Fabril, para a Ocupação e Democratização dos Espaços Público e Privado. Universidade Federal de Minas Gerais: Psicologia: Teoria e Pesquisa Abr-Jun 2009, Vol. 25 n. 2, pp. 237-244.

TICKNER, J Ann. Gender in International Relations: Feminist Perspectives on Achieving Global Security. New York: Columbia University Press, 1992.

TRUE, Jacqui. Feminism. In: BURCHILL, al. Theories of International Relations. New York: Palgrave Macmillam， 2005， p. 213235.

UN WOMEN. Annual report (2015-2016). New York: 2016. 